\title{
Glutamate receptors in the dorsal hippocampus mediate the acquisition, but not the expression, of conditioned place aversion induced by acute morphine withdrawal in rats
}

\author{
Yuan-yuan HOU, Yao LIU, Shuo KANG, Chuan YU, Zhi-qiang CHI, Jing-gen LIU*
}

State Key Laboratory of Drug Research, Shanghai Institute of Materia Medica, Chinese Academy of Sciences, Shanghai 201203, China

Aim: To evaluate the role of glutamate receptors in the dorsal hippocampus (DH) in the motivational component of morphine withdrawal. Methods: NMDA receptor antagonist D-AP5 $(5 \mu \mathrm{g} / 0.5 \mu \mathrm{L}$ per side) or AMPA receptor antagonist NBQX $(2 \mu \mathrm{g} / 0.5 \mu \mathrm{L}$ per side) was microinjected into DH of rats. Conditioned place aversion (CPA) induced by naloxone-precipitated morphine withdrawal were assessed.

Results: Preconditioning microinjection of D-AP5 or NBQX into the DH impaired the acquisition of CPA in acute morphine-dependent rats. However, intra-DH microinjection of D-AP5 or NBQX after conditioning but before the testing session had no effect on the expression of CPA.

Conclusion: Our results suggest that NMDA and AMPA receptors in the dorsal hippocampus are involved in the acquisition, but not in the expression, of the negative motivational components of acute morphine withdrawal in rats.

Keywords: NMDA receptors; AMPA receptors; hippocampus; morphine withdrawal; conditioned place aversion; Rats, Sprague-Dawley; microinjections

Acta Pharmacologica Sinica (2009) 30: 1385-1391; doi: 10.1038/aps.2009.130; published online 21 Sep 2009

\section{Introduction}

The development of opiate abuse, defined as a compulsive drug-taking associated with a loss of control, is driven by two distinct motivational factors: the rewarding effects of the drug (positive reinforcement) and the avoidance of withdrawal symptoms (negative reinforcement). Recently, the mechanisms of negative reinforcement have received considerable attention $^{[1,2]}$. Withdrawal from acute or chronic opiate exposure elicits a broad range of somatic symptoms and arouses assorted negative emotional states (eg, anxiety, irritability, and dysphoria). Clinical evidence suggests that the affective aspect of opiate withdrawal may play a more important role than its physical counterpart in driving drug craving and relapse to compulsive drug use by functioning as a negative motivation $^{[3,4]}$. An increasing number of studies have focused on elucidating the motivational effects of drug withdrawal in animals. One popular method for such research involves

* To whom correspondence should be addressed.

E-mail jgliu@mail.shcnc.ac.cn

Received 2009-05-19 Accepted 2009-07-15 studying a conditioned place aversion (CPA) paradigm, in which the negative affective component of opiate withdrawal is paired with a particular environment by conditioning training. The animals then avoid the previously paired environment when re-exposed to this environment in a drug-free state, reflecting the expression of the negative motivational effect of opiate withdrawal.

Glutamate, the predominant excitatory neurotransmitter in the central nervous system, is crucial for the development of major aspects of addiction, including craving, relapse and withdrawal ${ }^{[5,6]}$. Recent research supports the involvement of the glutamatergic system in the negative motivational component of opiate withdrawal. For instance, systemic administration of the NMDA-receptor antagonist MK-801, AMPAreceptor antagonist GYKI 52466 and glutamate release inhibitor riluzole impaired motivational signs of morphine withdrawal ${ }^{[7,8]}$. Furthermore, the inhibition of glutamate receptors in the central nucleus of the amygdala diminished morphine withdrawal-induced $\mathrm{CPA}^{[9]}$.

The hippocampus has the highest density of glutamatergic input in the brain and is anatomically connected with other 
brain regions that have been implicated in the motivational components of opiate withdrawal, such as the amygdala ${ }^{[9-11]}$. Immunohistochemical studies have shown that opiate withdrawal increases the expression of $c$-fos mRNA, an immediateearly gene used as a marker of neuronal activity, in the hippocampal CA1 region ${ }^{[12]}$. Furthermore, we recently found that excitotoxic lesions of the dorsal hippocampus, but not the ventral hippocampus (Figure S1 and Figure S2), impaired morphine withdrawal-induced CPA, indicating the involvement of the dorsal hippocampus in the motivational effects of opiate withdrawal. In addition, Guo et al reported that acute or chronic morphine treatment decreased the extracellular glutamate concentration in the hippocampus, whereas naloxoneprecipitated withdrawal enhanced the release of glutamate in the hippocampus ${ }^{[13]}$. These findings suggest the possibility that the glutamatergic system in the dorsal hippocampus may be involved in the motivational components of morphine withdrawal.

We here investigate the role of glutamate receptors within the dorsal hippocampus during the acquisition and expression of conditioned place aversion induced by acute morphine withdrawal.

\section{Materials and methods Subjects}

Sprague-Dawley male rats (clean grade) weighing 220-250 g were obtained from the Laboratory Animal Center, Chinese Academy of Sciences (Shanghai, China). Rats were housed 2-3 per cage and maintained on a 12-h light/dark cycle with access to food and water ad libitum. All experimental procedures were in strict accordance with the National Institutes of Health Guide for the Care and Use of Laboratory Animals.

\section{Surgery}

Rats were anesthetized using sodium pentobarbital $(50 \mathrm{mg} / \mathrm{kg}$, ip), treated with atropine sulfate $(0.2 \mathrm{mg} / \mathrm{kg}$, ip) and then placed in a stereotaxic apparatus (Narishige, Tokyo, Japan) with the incisor bar set at $-3.3 \mathrm{~mm}$ relative to the interaural line. The scalp was incised and retracted to expose the skull. Small burr holes were drilled through the skull to allow the guide cannulae to pass into the brain. The guide cannulae (23 gauge) were implanted bilaterally into the dorsal hippocampus using the following coordinates: anteroposterior (AP), $-3.80 \mathrm{~mm}$ from bregma; mediolateral (ML), $\pm 2.5 \mathrm{~mm}$ from the midline, dorsoventral (DV), $-1.5 \mathrm{~mm}$ from the skull ${ }^{[14]}$. Three surgical screws were implanted into the skull as anchors. The cannulae and the screws were affixed to the skull with dental cement. Insect pins ( $0.5 \mathrm{~mm}$ beyond the tip of guide cannula) were inserted into the cannulae to maintain patency and were removed only for the infusions. All rats were given 7-10 d for postsurgical recovery before commencing behavioral training.

\section{Conditioned place aversion \\ Apparatus}

A CPA apparatus $[60 \mathrm{~cm}($ length $) \times 30 \mathrm{~cm}($ width $) \times 30 \mathrm{~cm}$ (height)] made of Plexiglas was divided into two equal-size compartments by a partition with an opening $(10 \times 10 \mathrm{~cm})$ at one end, which allowed rats free access to each compartment. Two compartments were distinguished by visual and tactile cues: one compartment had white walls with a textured floor, whereas the other compartment had black walls with a smooth floor. Another partition without an opening was used to confine the rat to a given compartment in the conditioning session of the CPA procedure.

\section{Procedures}

The method to establish conditioned place aversion was similar to that employed by White et al ${ }^{[15]}$. The CPA procedure consisted of three sessions: pre-conditioning, conditioning and testing. In the pre-conditioning session, rats were allowed to freely explore the entire apparatus for $15 \mathrm{~min}$. Time spent in each compartment was determined automatically using a computer system (AniLab v2.0, AniLab Software \& Instrument Co Ltd, Ningbo, China). There was no significant difference between the time spent in the smooth floor compartment $(474.9 \pm 18.0 \mathrm{~s}, n=62)$ and that in the textured floor compartment $(425.1 \pm 18.0 \mathrm{~s}, n=62)$ during the pre-conditioning session. Conditioning took place over the next $2 \mathrm{~d}$. On the first day, the rats were injected with saline $(1 \mathrm{~mL} / \mathrm{kg}, \mathrm{sc})$ and then returned to home cages. Four hours later, they were again given saline and then confined to one or the other compartment in a counterbalanced manner for $30 \mathrm{~min}$. On the second day, the rats were injected with either morphine $(10 \mathrm{mg} / \mathrm{kg}, \mathrm{sc})$ or saline $(1 \mathrm{~mL} / \mathrm{kg}, \mathrm{sc})$ and then returned to their home cages. Four hours later, they were injected with naloxone $(0.3 \mathrm{mg} / \mathrm{kg}, \mathrm{sc})$ and then confined to the compartment they did not occupy on the first day for $30 \mathrm{~min}$. This compartment will be referred to as the "drug-paired compartment". In the testing session (24 $\mathrm{h}$ after the conditioning trial), all rats were allowed to freely explore the entire apparatus for $15 \mathrm{~min}$ and the amount of time spent in each compartment was recorded. CPA score is defined as time in the drug-paired compartment during the testing session minus time during the preconditioning session.

\section{Drugs and intracerebral microinjection}

Morphine hydrochloride was purchased from Qinghai Pharmaceutical General Factory (Qinghai, China). Naloxone hydrochloride, D-2-Amino-5-phosphonovaleric acid (D-AP5) and NBQX disodium salt were supplied by Sigma-Aldrich (St Louis, MO, USA). D-AP5 and NBQX were dissolved in PBS and other drugs were dissolved in saline before use. Bilateral microinfusions were made through 31-gauge injection cannulae ( $2.0 \mathrm{~mm}$ beyond the tip of guide cannulae) at a rate of $0.5 \mu \mathrm{L} / \mathrm{min}$ using a microsyringe pump (Harvard Apparatus, South Natick, MA, USA) over $1 \mathrm{~min}$. The injection cannulae were kept in place for an additional $2 \mathrm{~min}$. The dose of D-AP5 and NBQX was chosen based on pilot experiments and previous studies ${ }^{[16,17]}$. To determine the effects of D-AP5 and NBQX on the acquisition of CPA, D-AP5 and NBQX were microinjected into the dorsal hippocampus $10 \mathrm{~min}$ before paring on the second day of the conditioning session. To determine the effects of D-AP5 and NBQX on the expression of CPA, D-AP5 

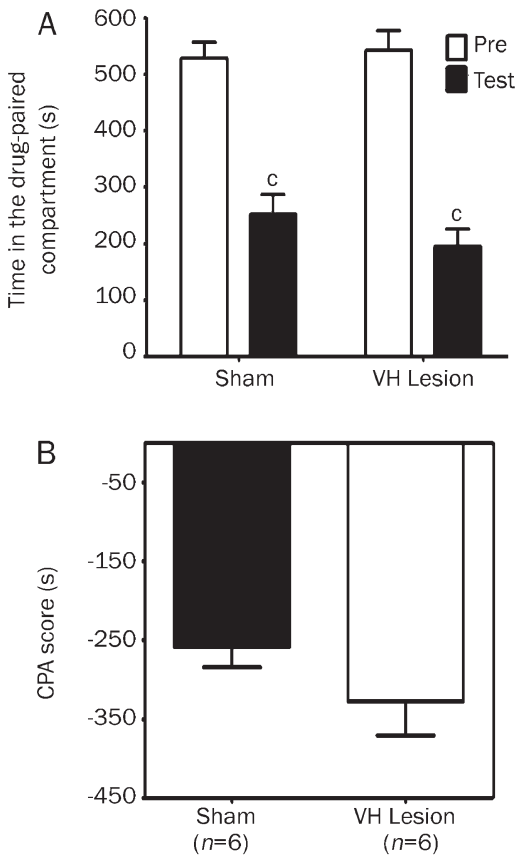

Figure S1. Effects of excitotoxic lesions of the ventral hippocampus on the acquisition of conditioned place aversion induced by naloxoneprecipitated morphine withdrawal in morphine-treated rats. Ibotenic acid $(10 \mu \mathrm{g} / \mu \mathrm{L})$ was microinjected into the ventral hippocampus $(0.15 \mu \mathrm{L}$ per site) using the following coordinates: (a) AP, $-4.9 \mathrm{~mm}, \mathrm{ML}, \pm 4.8 \mathrm{~mm}$, DV, -5.5 and $-4.6 \mathrm{~mm}$; (b) AP, $-5.2 \mathrm{~mm}, \mathrm{ML}, \pm 4.0 \mathrm{~mm}$, DV, -7.5 and -4.4 ; (c) AP, $+5.5 \mathrm{~mm}, \mathrm{ML}, \pm 5.0 \mathrm{~mm}$, DV, -6.1 and $-5.3 \mathrm{~mm}$. The columns show the time spent in the drug-paired compartment in the preconditioning (Pre) or testing (test) sessions (A) and the CPA score (B). Data are expressed as means \pm SEM. ${ }^{c} P<0.01$ compared with the corresponding preconditioning session (Student's $t$ test). VH: ventral hippocampus.

and NBQX were microinjected into the dorsal hippocampus 20 min before the testing session.

\section{Histology}

After behavioral testing, all rats were deeply anesthetized with sodium pentobarbital and perfused transcardially with PBS, followed by $10 \%$ formalin. The brains were removed and stored in a $30 \%$ sucrose $/ 10 \%$ formalin solution for 2-3 $\mathrm{d}$. Coronal sections (50 $\mu \mathrm{m}$ thick) were cut on a cryostat (Leica,

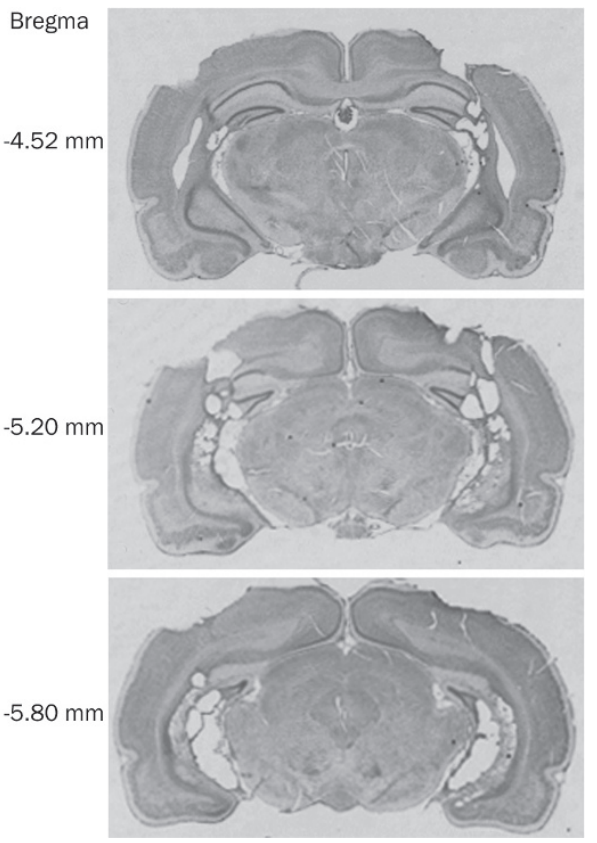

Figure S2. Representative photographs of cresyl violet-stained coronal sections showing the ventral hippocampus lesions.

Nussloch, Germany), stained with cresyl violet and then examined by light microscopy to determine the injection site.

\section{Data analysis}

Data are represented as mean \pm SEM. All data were analyzed with one-way ANOVA or Student's $t$ tests, where appropriate. Post hoc testing was performed with Newman-Keuls Test. Differences with $P<0.05$ were considered statistically significant.

\section{Results}

\section{Histology}

The injection sites for all rats included in the analysis of this experiment (no rats from the initial 62 were discarded) are illustrated in Figure 1. All injection sites were located in the dorsal hippocampus. Injection sites for vehicle, D-AP5 and NBQX were basically the same; thus no difference among three conditions resulted from differential injection sites.

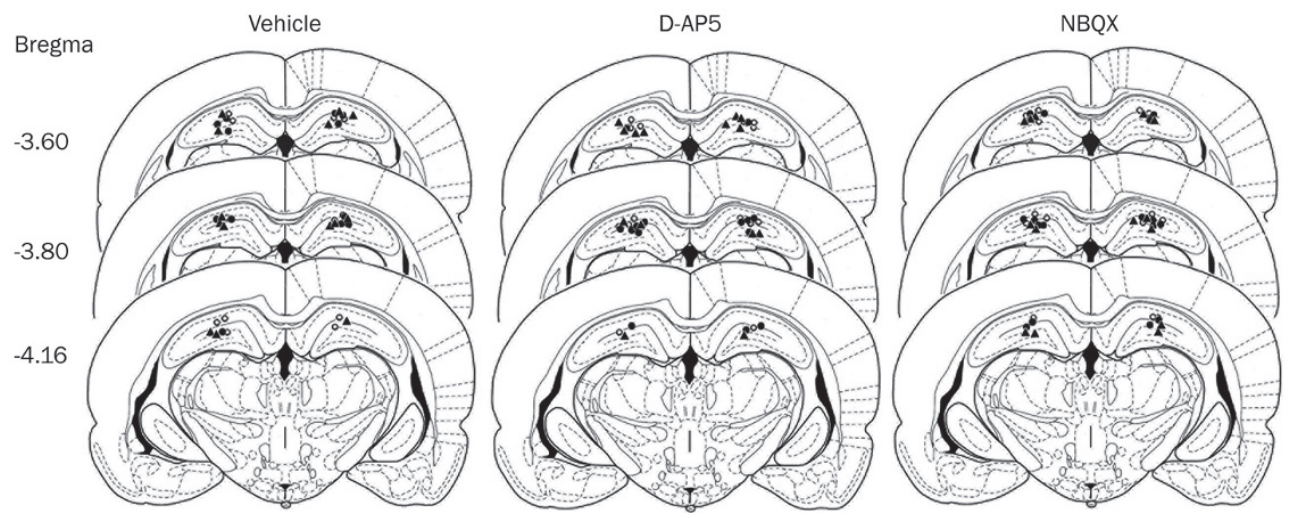

Figure 1. Schematic representation of injection sites in the dorsal hippocampus for all rats included in the experiments ( $\circ$, preconditioning microinjection in saline-treated rats; •, preconditioning microinjection in morphine-treated rats; $\boldsymbol{\Lambda}$, pretesting microinjection in morphine-treated rats). Numbers to the left of the coronal sections represent the distance $(\mathrm{mm})$ from bregma in the anterior-posterior axis. 
Effects of intra-DH injection of D-AP5 or NBQX on the acquisition of conditioned place aversion induced by naloxone-precipitated morphine withdrawal

Conditioned place aversion (CPA) is a form of associative learning in which an animal avoids an environment that had been paired previously with drug withdrawal. The hippocampus is vital for mediating the encoding and consolidation of associative memory processes which are mediated particularly by glutamate receptors ${ }^{[18-20]}$. To determine whether glutamate receptors in the dorsal hippocampus are involved in the acquisition of morphine withdrawal-induced CPA, the competitive NMDA receptor antagonist D-AP5 (5 $\mu \mathrm{g} / 0.5$ $\mu \mathrm{L}$ per side) or the competitive AMPA receptor antagonist NBQX ( $2 \mu \mathrm{g} / 0.5 \mu \mathrm{L}$ per side) was bilaterally microinfused into the dorsal hippocampus $10 \mathrm{~min}$ before naloxone injection during the conditioning session. In the rats microinjected with vehicle into the bilateral $\mathrm{DH}, \mathrm{CPA}$ was dramatically induced by naloxone injection following a single exposure to morphine, consistent with previous studies ${ }^{[15,21]}$. In intra-DH vehicle-injected rats, the time spent in the drug-paired compartment during the testing session was significantly shorter at $278.8 \pm 30.8 \mathrm{~s}(P<0.01$, Student's $t$ test $)$ than that spent during the preconditioning session (620.7 $\pm 40.3 \mathrm{~s}$ ) (Figure 2A). Microinjection of D-AP5 and NBQX into the DH of the morphinetreated rats attenuated the acquisition of CPA induced by naloxone-precipitated morphine withdrawal. In the rats microinjected with D-AP5 or NBQX into the DH, there were no significant differences ( $P>0.05$, Student's $t$ test) between the time spent in the drug-paired compartment during the testing session (489.0 $\pm 43.7 \mathrm{~s}$ and $479.8 \pm 51.2 \mathrm{~s}$, respectively) and that spent during the preconditioning session $(575.7 \pm 36.1 \mathrm{~s}$ and $583.9 \pm 32.8$ s, respectively) (Figure $2 \mathrm{~A}$ ). CPA scores revealed an inhibition of morphine withdrawal-induced CPA behavior by the intra-DH injection of D-AP5 or NBQX (Figure 2B). Oneway ANOVA indicated a significant difference among groups $\left(F_{(2,18)}=10.09 ; P<0.01\right)$. Post hoc comparison by the NewmanKeuls test showed that D-AP5 $(-86.7 \pm 38.1 \mathrm{~s}, P<0.01)$ and NBQX $(-104.1 \pm 49.5 \mathrm{~s}, P<0.01)$ produced a significant attenuation of CPA score compared with the vehicle-injected morphinetreated group $(-341.9 \pm 33.6 \mathrm{~s})$.

To examine whether intra-DH injection of D-AP5 or NBQX produced conditioned place preference (CPP) or CPA in the absence of morphine treatment, D-AP5 or NBQX was injected into the bilateral dorsal hippocampus of salinetreated rats. No significant differences $(P<0.05$, Student's $t$ test) were observed in the vehicle, D-AP5 or NBQX-injected groups between the time spent in the drug-paired compartment during the testing session $(542.5 \pm 53.0 \mathrm{~s}, 565.6 \pm 59.8 \mathrm{~s}$ and $532.0 \pm 58.2 \mathrm{~s}$, respectively) and that spent during the preconditioning session $(553.4 \pm 25.4 \mathrm{~s}, 571.0 \pm 32.3 \mathrm{~s}$ and $537.9 \pm 33.4 \mathrm{~s}$, respectively) (Figure $3 \mathrm{~A})$. One-way ANOVA indicated no significant differences in CPA score among groups $\left(F_{(2,17)}=0.005\right.$; $P>0.05$ ) (Figure 3B). These data showed that neither CPP nor CPA was induced by intra-DH injection of vehicle, D-AP5 or NBQX, suggesting that D-AP5 and NBQX alone have no motivational effects when injected at this dose into the dorsal hippocampus.
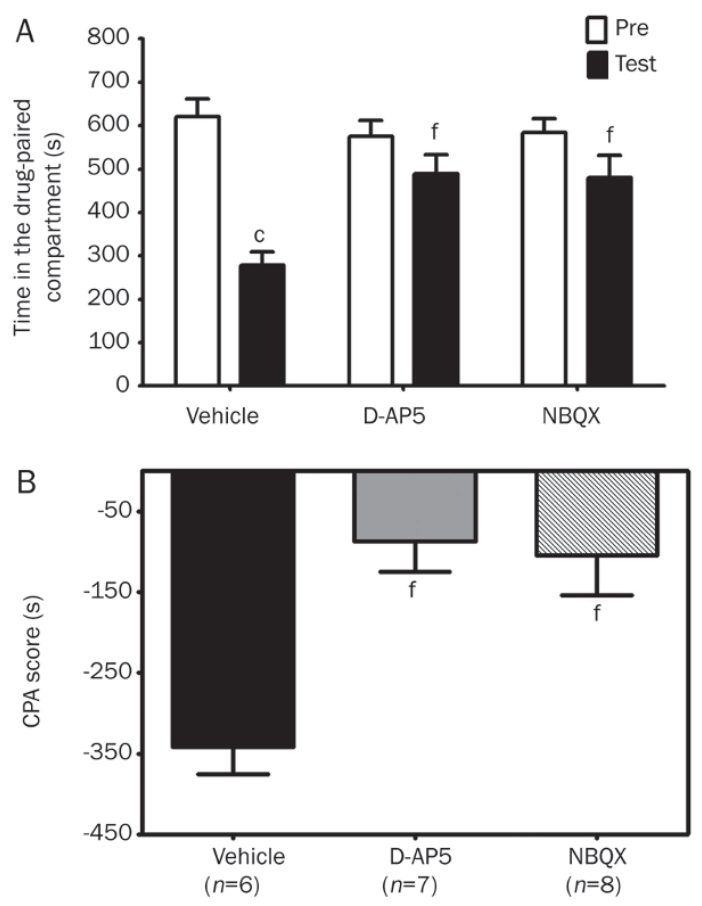

Figure 2. Effects of intra-DH infusion of D-AP5 or NBQX on the acquisition of conditioned place aversion induced by naloxone-precipitated morphine withdrawal in morphine-treated rats. D-AP5 (5 $\mu \mathrm{g} / 0.5 \mu \mathrm{L}$ per side), NBQX ( $2 \mu \mathrm{g} / 0.5 \mu \mathrm{L}$ per side) or vehicle $(0.5 \mu \mathrm{L} /$ side $)$ was bilaterally microinfused into the dorsal hippocampus $10 \mathrm{~min}$ before pairing on the second day of the conditioning session. The columns show the time spent in the drugpaired compartment during the preconditioning (Pre) or testing (test) sessions (A) and the CPA score (B). The CPA score is defined as time in the drug-paired compartment during the testing session minus the time spent during the preconditioning session. Data are expressed as means \pm SEM. ${ }^{c} P<0.01$ compared with the corresponding preconditioning session (Student's $t$ test); ${ }^{\text {f }} P<0.01$ compared with vehicle injected rats (one-way ANOVA with Newman-Keuls post hoc test).

Effects of intra-DH injection of D-AP5 or NBQX on the expression of conditioned place aversion induced by naloxone-precipitated morphine withdrawal

Considerable evidence has shown that the dorsal hippocampus is involved in contextual memory retrieval in several Pavlovian conditioning tasks, such as fear conditioning and morphine-induced $\mathrm{CPP}^{[22-25]}$. In the CPA testing session, re-exposure to the training context elicited retrieval of the morphine withdrawal memory and the negative motivation induced by the morphine withdrawal-paired environment was then expressed as aversion. To examine the effects of D-AP5 or NBQX on the expression of the negative motivational effect of morphine withdrawal, each of the drugs was bilaterally microinjected into the dorsal hippocampus $20 \mathrm{~min}$ before the testing session. Figure 4 indicates that the intra-DH injection of D-AP5 or NBQX did not induce a change in the expression of CPA in the morphine-treated rats. In the vehicle, D-AP5 or NBQX-injected groups, significant differences $(P<0.01$, Student's $t$ test) were observed between the time spent in the 

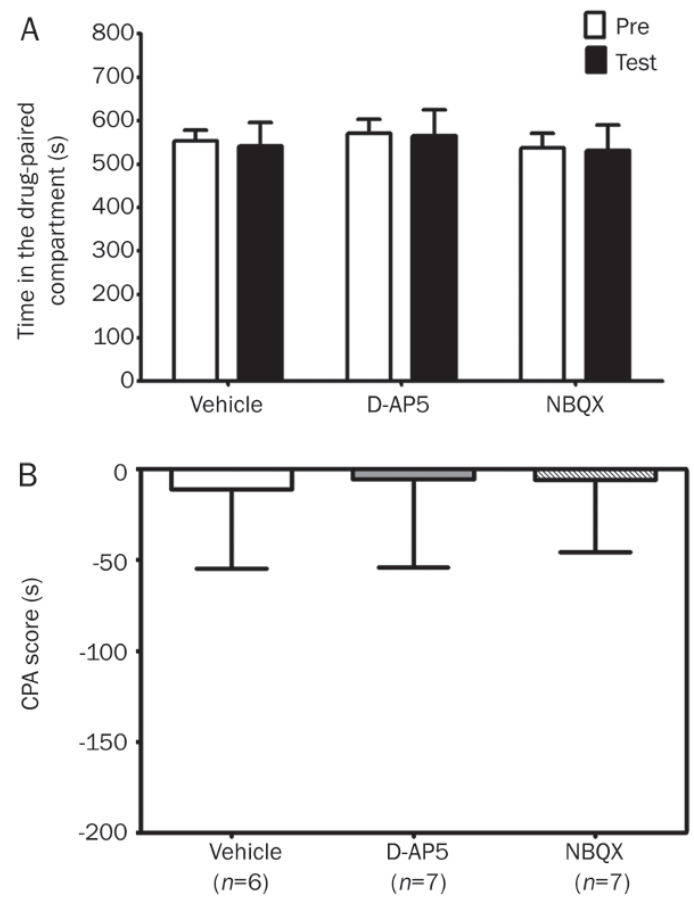

Figure 3. Effects of intra-DH infusion of D-AP5 or NBQX on conditioned place aversion in saline-treated rats. The columns show the time spent in the drug-paired compartment in the preconditioning (Pre) or testing (test) sessions (A) and the CPA score (B). D-AP5 ( $5 \mu \mathrm{g} / 0.5 \mu \mathrm{L}$ per side), NBQX (2 $\mu \mathrm{g} / 0.5 \mu \mathrm{L}$ per side) or vehicle $(0.5 \mu \mathrm{L} /$ side $)$ was bilaterally microinfused into the dorsal hippocampus $10 \mathrm{~min}$ before pairing on the second day of the conditioning session. Data are expressed as means \pm SEM.

drug-paired compartment during the testing session (202.8 \pm $52.8 \mathrm{~s}, 212.5 \pm 74.0 \mathrm{~s}$ and $187.4 \pm 46.2 \mathrm{~s}$, respectively) and the time spent during the preconditioning session $(630.6 \pm 35.5 \mathrm{~s}$, $583.9 \pm 46.8 \mathrm{~s}$ and $575.8 \pm 58.8 \mathrm{~s}$, respectively), indicative of the formation of morphine-withdrawal induced CPA(Figure 4A). One-way ANOVA indicated no significant difference in CPA score among the groups $\left(F_{(2,18)}=0.15 ; P>0.05\right)$ (Figure $\left.4 \mathrm{~B}\right)$.

\section{Discussion}

The hippocampus is an important part of the limbic system that has been widely reported to be involved in many important aspects of addiction, including craving and relapse. However, very few studies have addressed the role of the hippocampus in opiate withdrawal. We recently found that excitotoxic lesions of the dorsal hippocampus, but not the ventral hippocampus, impaired CPA induced by morphine withdrawal (supplemental data in Figure S1 and Figure S2), suggesting that there is a functional dissociation between the dorsal and ventral hippocampus with respect to the motivational effect of morphine withdrawal. This finding was consistent with previous studies showing that the dorsal hippocampus and ventral hippocampus play different roles in a variety of learning and memory tasks, such as fear conditioning, cocaine place conditioning and spatial learning ${ }^{[26-28]}$. The possible mechanisms underlying this functional dissociation
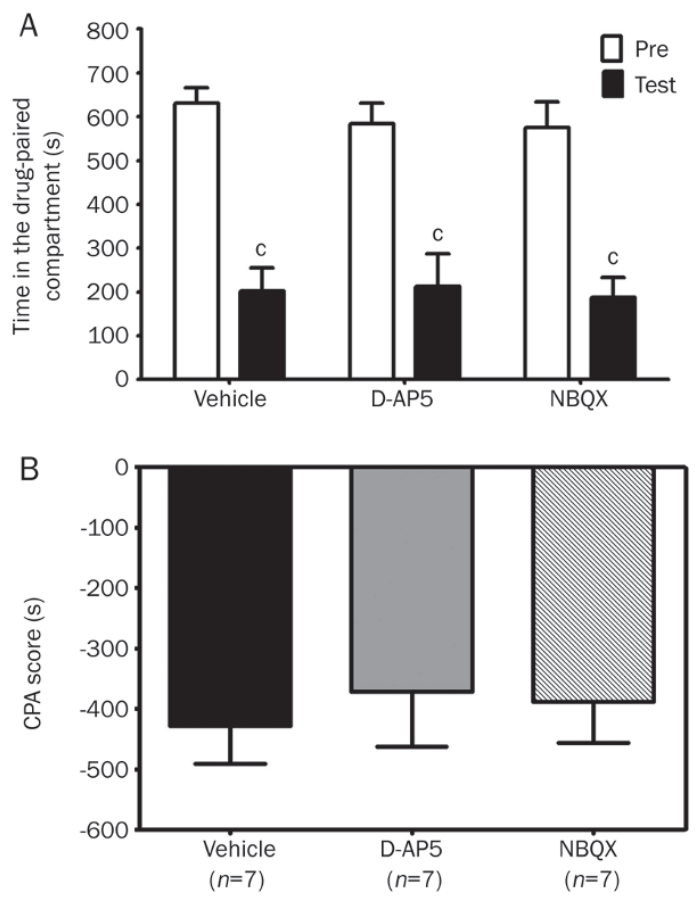

Figure 4. Effects of intra-DH infusion of D-AP5 or NBQX on the expression of conditioned place aversion induced by naloxone-precipitated morphine withdrawal in morphine-treated rats. D-AP5 $(5 \mu \mathrm{g} / 0.5 \mu \mathrm{L}$ per side), NBQX ( $2 \mu \mathrm{g} / 0.5 \mu \mathrm{L}$ per side) or vehicle $(0.5 \mu \mathrm{L}$ per side) was bilaterally microinfused into the dorsal hippocampus $20 \mathrm{~min}$ before the testing session. The columns show the time spent in the drug-paired compartment in the preconditioning (Pre) or testing (test) sessions (A) and the CPA score (B). Data are expressed as means \pm SEM. ${ }^{\circ} P<0.01$ compared with the corresponding preconditioning session (Student's $t$ test).

remain unclear.

In the present study, we found that a preconditioning intraDH injection of the competitive NMDA receptor antagonist D-AP5 or the AMPA receptor antagonist NBQX attenuated acute morphine withdrawal-induced CPA, whereas pretesting injections of the same did not. These results suggest that the glutamatergic system of the dorsal hippocampus is required for the formation, but not the expression, of the negative motivational aspects of opiate withdrawal. Our present results are consistent with previous findings that the central glutamate system is involved in the motivational aspects of opiate withdrawal ${ }^{[7-9]}$ and extend these findings by revealing that the dorsal hippocampus is a key area of the brain for this involvement. In addition, the present study provides further insight into which transmitter system in the dorsal hippocampus is responsible for the motivational effect of morphine withdrawal.

$\mathrm{CPA}$ is a Pavlovian conditioning paradigm wherein drug withdrawal is paired with a particular environment, triggering an association between the negative affective consequences of withdrawal and this context. Once the animals are re-exposed to the paired environment in a drug-free state, this association leads to avoidance of the paired environment. Thus, CPA 
reflects a process of learning and memory. The persistent changes in behavior and psychological function that occur as a consequence of experience are thought to be mediated by the reorganization or strengthening of synaptic connections in specific neural circuits, and synaptic plasticity is thus thought to play a critical role in learning and memory. Long-term potentiation (LTP), a form of activity-dependent synaptic plasticity that strengthens active synapses, has long been thought to be a possible neural mechanism underling learning and memory ${ }^{[2,30]}$.

The hippocampus is a key region of the brain for both the encoding and the consolidation of associative memory ${ }^{[18-20]}$. Extensive evidence supports the idea that the glutamatergic system, acting via NMDA and AMPA receptors, plays a crucial role in the formation and maintenance of hippocampal LTP $^{[31-34]}$. For instance, substantial evidence indicates that NMDA-dependent actin polymerization is important for consolidation of the early phase of LTP into the late phase in adult rats in vivo ${ }^{[35,36]}$ and that increases in glutamate transmission by AMPA receptors can lead to a stabilization of dendritic spine morphology, LTP and memory ${ }^{[37]}$. Therefore, one possible explanation for the effects of glutamate antagonists D-AP5 or NBQX on morphine withdrawal-induced CPA observed in this study involves the disruption of associative learning during CPA training, which may lead to an impairment of the aversive morphine withdrawal memory formed by the association between naloxone-precipitated morphine withdrawal and environmental cues. Supporting this model, several studies have demonstrated that the inhibition of glutamate receptors in the hippocampus impaired the acquisition and consolidation of fear conditioning ${ }^{[38-40]}$, possibly due to the blockade of glutamate receptor-dependent synaptic plasticity ${ }^{[11,42]}$.

In the present study, we demonstrate that the intra-DH injection of D-AD5 and NBQX blocks the acquisition of morphine withdrawal-induced place aversion without affecting its expression. Our results thus reveal that the acquisition and the expression of CPA rely on different molecular mechanisms. Several previous studies have also shown that the glutamatergic system is distinctly involved in the acquisition and the expression of certain behaviors. For example, Quinn et al reported that blockade of the dorsal hippocampus NMDA receptors disrupted the acquisition of two forms of fear conditioning while differentially affecting their expression ${ }^{[39]}$. They also found that intra-DH injection of D-AP5 did not diminish the expression of contextual fear conditioning. Additionally, previous studies have shown that in the dorsal hippocampus, NMDA receptors were involved only in the acquisition, but not the expression, of morphine induced-CPP ${ }^{[43]}$, whereas dopamine and GABA receptors were required for the expression of morphine induced-CPP ${ }^{[23-25]}$. Although our study clearly showed that NMDA and AMPA receptors in the dorsal hippocampus are involved in the acquisition, but not the expression, of morphine withdrawal-induced CPA, further work is needed to address the mechanisms by which NMDA and AMPA receptors modulate synaptic plasticity (eg, actin rearrangement and LTP) in response to place aversion condition- ing and to determine the neurotransmitters that are involved in the expression of CPA.

\section{Acknowledgments}

This study was supported by the National Basic Research Program grant from the Ministry of Science and Technology of China (№ G2003CB515400) and (№ 2009CB522000), National Science Fund for Distinguished Young Scholar from the National Natural Science Foundation of China (№ 30425002) and a fund granted by the Chinese Academy of Sciences (No KSCXI/YW/R/68).

\section{Author contribution}

Yuan-yuan HOU designed and preformed the research and wrote the paper. Yao LIU helped with histology analysis. Shuo KANG and Chuan YU helped with animal training. Zhiqiang $\mathrm{CHI}$ provided consultation. Jing-gen LIU revised the paper.

\section{References}

1 Koob GF. Neurobiology of addiction. Toward the development of new therapies. Ann N Y Acad Sci 2000; 909: 170-85.

2 Hutcheson DM, Everitt BJ, Robbins TW, Dickinson A. The role of withdrawal in heroin addiction: enhances reward or promotes avoidance? Nat Neurosci 2001; 4: 943-7.

3 Jasinski DR, Johnson RE, Kocher TR. Clonidine in morphine withdrawal. Differential effects on signs and symptoms. Arch Gen Psychiatry 1985; 42: 1063-6.

4 Henningfield JE, Johnson RE, Jasinski DR. Clinical procedures for the assessment of abuse potential. In: Bozarth MA, editors. Methods of assessing the reinforcing properties of abused drugs. New York: Springer-Verlag; 1987. p573-90.

5 Tzschentke TM, Schmidt WJ. Glutamatergic mechanisms in addiction. Mol Psychiatry 2003; 8: 373-82.

6 Kalivas PW, Lalumiere RT, Knackstedt L, Shen H. Glutamate transmission in addiction. Neuropharmacology 2009; 56 Suppl 1: 169-73.

7 Kawasaki Y, Jin C, Suemaru K, Kawasaki H, Shibata K, Choshi T, et al. Effect of glutamate receptor antagonists on place aversion induced by naloxone in single-dose morphine-treated rats. Br J Pharmacol 2005; 145: $751-7$.

8 Jin C, Araki H, Kawasaki Y, Nagata M, Suemaru K, Shibata K, et al. The glutamate release inhibitor riluzole attenuates the formation of conditioned place aversion induced by naloxone in rats undergoing a single morphine exposure. Brain Res 2006; 1069: 120-6.

9 Watanabe T, Nakagawa T, Yamamoto R, Maeda A, Minami M, Satoh M. Involvement of glutamate receptors within the central nucleus of the amygdala in naloxone-precipitated morphine withdrawal-induced conditioned place aversion in rats. Jpn J Pharmacol 2002; 88: 399-406.

10 Kelsey JE, Arnold SR. Lesions of the dorsomedial amygdala, but not the nucleus accumbens, reduce the aversiveness of morphine withdrawal in rats. Behav Neurosci 1994; 108: 1119-27.

11 Pitkanen A, Pikkarainen M, Nurminen N, Ylinen A. Reciprocal connections between the amygdala and the hippocampal formation, perirhinal cortex, and postrhinal cortex in rat. A review. Ann N Y Acad Sci 2000; 911: 369-91.

12 Frenois F, Cador M, Caille S, Stinus L, Le Moine C. Neural correlates of the motivational and somatic components of naloxone-precipitated morphine withdrawal. Eur J Neurosci 2002; 16: 1377-89.

13 Guo M, Xu NJ, Li YT, Yang JY, Wu CF, Pei G. Morphine modulates glu- 
tamate release in the hippocampal CA1 area in mice. Neurosci Lett 2005; 381: 12-5.

14 Paxinos $\mathrm{G}$ and Watson C. The Rat Brain in Stereotaxic Coordinates (5th ed), Amsterdam: Elsevier Academic Press; 2005.

15 White DA, Hwang ML, Holtzman SG. Naltrexone-induced conditioned place aversion following a single dose of morphine in the rat. Pharmacol Biochem Behav 2005; 81: 451-8.

16 McDannald M, Kerfoot E, Gallagher M, Holland PC. Amygdala central nucleus function is necessary for learning but not expression of conditioned visual orienting. Eur J Neurosci 2004; 20: 240-8.

17 Matus-Amat P, Higgins EA, Sprunger D, Wright-Hardesty K, Rudy JW. The role of dorsal hippocampus and basolateral amygdala NMDA receptors in the acquisition and retrieval of context and contextual fear memories. Behav Neurosci 2007; 121: 721-31.

18 Small SA, Nava AS, Perera GM, DeLaPaz R, Mayeux R, Stern Y. Circuit mechanisms underlying memory encoding and retrieval in the long axis of the hippocampal formation. Nat Neurosci 2001; 4: 442-9.

19 McNaughton N, Hebb WJ. Pandemonium and catastrophic hypermnesia: the hippocampus as a suppressor of inappropriate associations. Cortex 2003; 39: 1139-63.

20 Kennedy PJ, Shapiro ML. Retrieving memories via internal context requires the hippocampus. J Neurosci 2004; 24: 6979-85.

21 Azar MR, Jones BC, Schulteis G. Conditioned place aversion is a highly sensitive index of acute opioid dependence and withdrawal. Psychopharmacology (Berl) 2003; 170: 42-50.

22 Maren S, Holt W. The hippocampus and contextual memory retrieval in Pavlovian conditioning. Behav Brain Res 2000; 110: 97-108.

23 Rezayof A, Zarrindast MR, Sahraei H, Haeri-Rohani A. Involvement of dopamine receptors of the dorsal hippocampus on the acquisition and expression of morphine-induced place preference in rats. J Psychopharmacol 2003; 17: 415-23.

24 Rezayof A, Razavi S, Haeri-Rohani A, Rassouli Y, Zarrindast MR. GABA(A) receptors of hippocampal CA1 regions are involved in the acquisition and expression of morphine-induced place preference. Eur Neuropsychopharmacol 2007; 17: 24-31.

25 Zarrindast MR, Massoudi R, Sepehri H, Rezayof A. Involvement of $\mathrm{GABA}(\mathrm{B})$ receptors of the dorsal hippocampus on the acquisition and expression of morphine-induced place preference in rats. Physiol Behav 2006; 87: 31-8.

26 McEown K, Treit D. The role of the dorsal and ventral hippocampus in fear and memory of a shock-probe experience. Brain Res 2009; 1251: 185-94.

27 Meyers RA, Zavala AR, Neisewander JL. Dorsal, but not ventral, hippocampal lesions disrupt cocaine place conditioning. Neuroreport 2003; 14: 2127-31.
28 Pothuizen HH, Zhang WN, Jongen-Relo AL, Feldon J, Yee BK. Dissociation of function between the dorsal and the ventral hippocampus in spatial learning abilities of the rat: a within-subject, within-task comparison of reference and working spatial memory. Eur J Neurosci 2004; 19: 705-12.

29 Bliss TV, Collingridge GL. A synaptic model of memory: long-term potentiation in the hippocampus. Nature 1993; 361: 31-9.

30 Malenka RC, Nicoll RA. Long-term potentiation - a decade of progress? Science 1999; 285: 1870-4.

31 Riedel G, Platt B, Micheau J. Glutamate receptor function in learning and memory. Behav Brain Res 2003; 140: 1-47.

32 Watt AJ, Sjostrom PJ, Hausser M, Nelson SB, Turrigiano GG. A proportional but slower NMDA potentiation follows AMPA potentiation in LTP. Nat Neurosci 2004; 7: 518-24.

33 Nicoll RA, Malenka RC. Expression mechanisms underlying NMDA receptor-dependent long-term potentiation. Ann N Y Acad Sci 1999; 868: 515-25.

34 MacDonald JF, Jackson MF, Beazely MA. Hippocampal long-term synaptic plasticity and signal amplification of NMDA receptors. Crit Rev Neurobiol 2006; 18: 71-84.

35 Maletic-Savatic M, Malinow R, Svoboda K. Rapid dendritic morphogenesis in CA1 hippocampal dendrites induced by synaptic activity. Science 1999; 283: 1923-7.

36 Matus A. Actin-based plasticity in dendritic spines. Science 2000; 290: 754-8.

37 Lamprecht R, LeDoux J. Structural plasticity and memory. Nat Rev Neurosci 2004; 5: 45-54.

38 Bast T, Zhang WN, Feldon J. Dorsal hippocampus and classical fear conditioning to tone and context in rats: effects of local NMDAreceptor blockade and stimulation. Hippocampus 2003; 13: 657-75.

39 Quinn JJ, Loya F, Ma QD, Fanselow MS. Dorsal hippocampus NMDA receptors differentially mediate trace and contextual fear conditioning. Hippocampus 2005; 15: 665-74.

40 Burman MA, Gewirtz JC. Hippocampal activity, but not plasticity, is required for early consolidation of fear conditioning with a short trace interval. Eur J Neurosci 2007; 25: 2483-90.

41 Levenson J, Weeber E, Selcher JC, Kategaya LS, Sweatt JD, Eskin A. Long-term potentiation and contextual fear conditioning increase neuronal glutamate uptake. Nat Neurosci 2002; 5: 155-61.

42 Maren S. Synaptic mechanisms of associative memory in the amygdala. Neuron 2005; 47: 783-6.

43 Zarrindast MR, Lashgari R, Rezayof A, Motamedi F, Nazari-Serenjeh F. NMDA receptors of dorsal hippocampus are involved in the acquisition, but not in the expression of morphine-induced place preference. Eur J Pharmacol 2007; 568: 192-8. 